\title{
CHOQUE CIRCULATÓRIO
}

\author{
CIRCULATORY SHOCK
}

Walter Villela de Andrade Vicente ${ }^{1}$, Alfredo José Rodrigues ${ }^{1}$, Jairo Rosa e Silva Júnior ${ }^{2}$

\begin{abstract}
'Docente da Divisão de Cirurgia Torácica e Cardiovascular do Departamento de Cirurgia e Anatomia; ${ }^{2} \mathrm{MD}$, PhD, Divisão de Cirurgia Torácica e Cardiovascular do Departamento de Cirurgia e Anatomia. Faculdade de Medicina de Ribeirão Preto - USP.

Corresopondência: Departamento. de Cirurgia e Anatomia da Faculdade de Medicina de Ribeirão Preto - USP. Av. Bandeirantes, 3900. CEP; 1408-900. email: alfredo@fmrp.usp.br
\end{abstract}

Vicente WVA, Rodrigues AJ, Silva Júnior JR. Choque Circulatório. Medicina (Ribeirão Preto) 2008; 41 (4): 437-48.

RESUMO: São apresentados os aspectos práticos da fisiologia cardiovascular e do sistema circulatório para a compreensão das anormalidades hemodinâmicas nos diferentes quadros de choque circulatório. Também são apresentados os métodos terapêuticos básicos para o choque circulatório.

Descritores: Choque. Choque/Diagnóstico. Choque Circulatório.

\section{1- INTRODUÇÃO}

Aos médicos em geral pode, à primeira vista, parecer desnecessário interessar se pelo choque circulatório, uma vez que, atualmente, esses pacientes são tratados em ambiente de terapia intensiva, sob os cuidados de médicos especialistas.

É preciso, todavia, considerar que o sucesso terapêutico depende muito da percepção precoce do estado de choque circulatório por parte, quase sempre, do médico que presta o primeiro atendimento. Por outro lado, o intensivista, com frequiência, terá de interagir com o colega que lhe encaminhou o paciente, na tomada de decisões terapêuticas que envolvam, diretamente, a participação deste último. Por exemplo, pode ser necessário que o otorrinolaringologista intervenha cirurgicamente para coibir hemorragias ou drenar coleções purulentas que possam ser responsáveis ou agravantes do quadro de choque circulatório.

Neste capítulo enfocamos o assunto sob prisma eminentemente prático, ressaltando aspectos básicos da Fisiologia cardiovascular, com o recurso de fórmulas físicas simples, de fácil compreensão, e que, transpostas para o sistema circulatório, com as devidas abstrações, permitem, de maneira lógica e descomplicada, tanto entender as profundas alterações hemodinâmicas existentes nos diferentes quadros de choque circulatório, como inferir as medidas terapêuticas básicas aplicáveis em cada situação.

\section{2- DEFINIÇÃO}

O choque circulatório é uma condição clínica aguda, representada pela incapacidade do sistema cardiovascular em manter perfusão suficiente para atender à homeostase, de modo a desencadearem se profundas alterações do metabolismo celular que, se não corrigidas a tempo, levam à disfunção de múltiplos órgãos e, finalmente, à morte (Figura 1).

Essa definição, por si só, diferencia o choque circulatório da síncope pelo fato de que, nesta última, mecanismos de auto regulação cardiocirculatória são capazes de, em questão de minutos, reverter o desarranjo hemodinâmico causador da perda da consciência por déficit transitório da perfusão cerebral. 


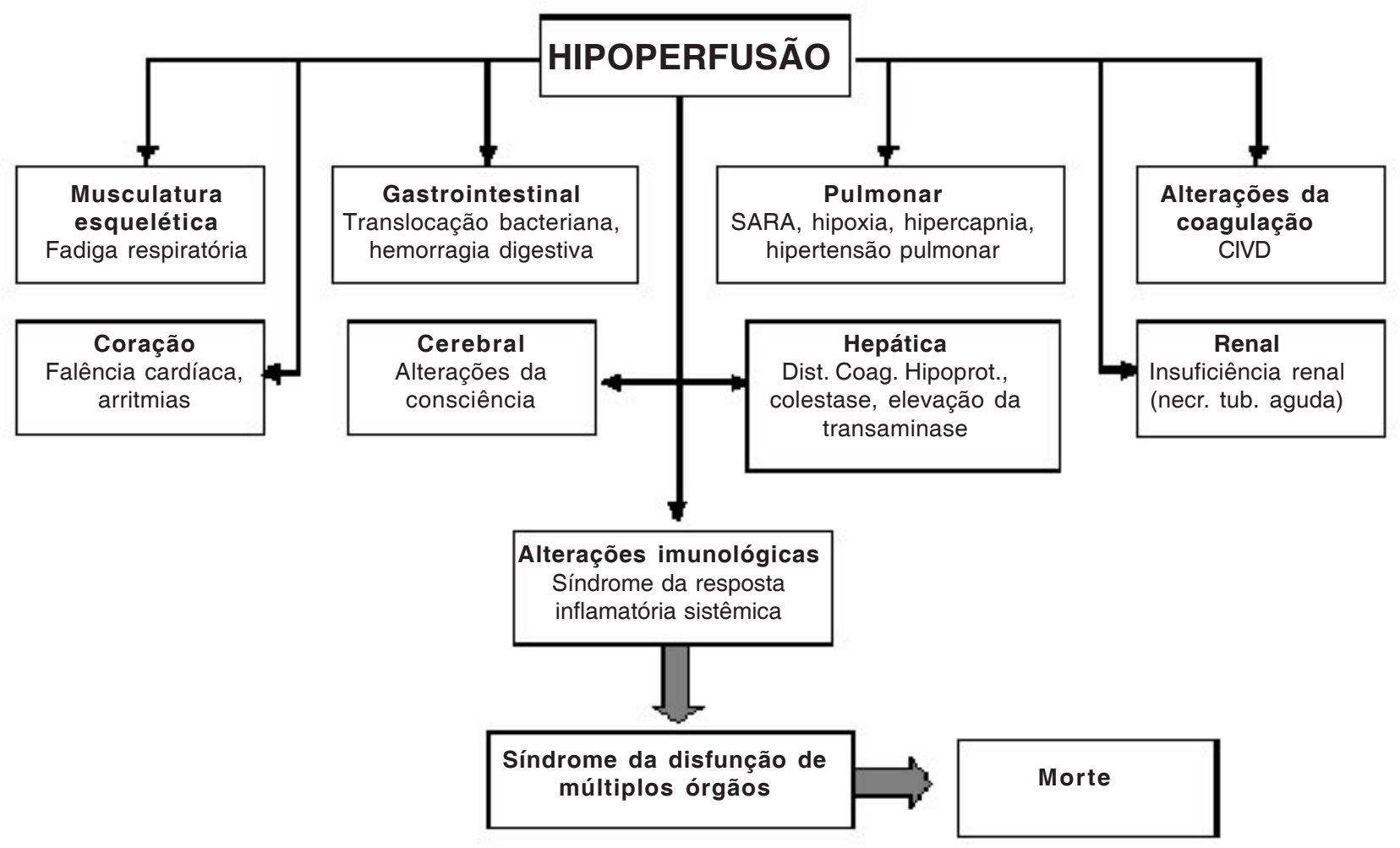

Figura 1: Representação esquemática da evolução do choque circulatório.

\section{3- CLASSIFICAÇÃ̃o}

A classificação do choque circulatório é útil, particularmente, para fins didáticos, e baseia se, em geral, no principal mecanismo desencadeante, embora se deva reconhecer que, em várias situações, possam coexistir dois ou mais mecanismos na gênese e/ ou na evolução do choque.

Considerando se que, na sua essência, o sistema circulatório pode ser reduzido a um circuito hidrodinâmico simples, composto por um conjunto de vasos através dos quais um fluido é bombeado, desenvolveu se uma classificação ampla e simples do choque circulatório, em três grandes grupos, denominados hipovolêmico, cardiogênico e distributivo. Essa denominação pressupõe que o mecanismo deflagrador do choque tenha sido, respectivamente, a redução abrupta do volume circulante, a insuficiência cardíaca aguda ou um profundo desajuste do tônus vascular e/ou da microcirculação. Por conveniência, e ainda com base na etiopatogenia, a cada um deles acrescentaram se duas ou mais subdivisões, discriminadas a seguir.

\section{1- Choque hipovolêmíco}

Conforme o componente do fluido intravascular perdido, subdivide se em dois grandes grupos:

- Hemorrágico: perda sanguiínea quer para o meio interno (por exemplo, hemotórax), quer para o meio externo.

- Não hemorrágico: diarréia, poliúria, queimaduras extensas, desidratação.

\section{2- Choque cardiogênico}

Decorrente de disfunção miocárdica (infarto do miocárdio, miocardiopatias, contusão cardíaca, etc.).

- Obstrução da via de saída ventricular: por exemplo, embolia pulmonar a cavaleiro.

- Restrição ao enchimento ventricular: por exemplo endomiocardiofibrose, pericardite constritiva e tamponamento cardíaco.

- Distúrbios do ritmo cardíaco: por exemplo, bradi ou taquiarritmias.

- Disfunção valvar: avançada. 


\section{3- Choque distributivo}

- Toxêmíco: desencadeado por processos inflamatórios intensos (septicemia, traumas, queimaduras graves e pancreatite necro hemorrágica).

- Anafilático: deflagrado por reações inflamatórias secundárias a reações antígeno anticorpo.

- Neurogênico: determinado por abolição ou redução acentuada do tônus vasomotor por disfunção central.

- Farmacológico: quando consequiente à ação direta de agentes químicos exógenos.

O leitor verifica que, na classificação apresentada, não se encontra o choque traumático, um dos mais freqüentemente vistos nos grandes núcleos urbanos e nos confrontos armados. Essa ausência explica se por mesclarem se na sua etiopatogenia vários fatores, concomitantes ou não, dentre os quais a perda volêmica, o trauma tissular, a dor intensa e a contaminação de ferimentos com sepse subseqüente.

Na presença de ferimento cardíaco ou pleuropulmonar, o choque traumático pode ser, rapidamente, fatal, devido tanto a tamponamento cardíaco determinado por acúmulo de sangue no saco pericárdico, o que é mais frequiente, ou por pneumotórax hipertensivo, com compressão não só mediastinal e, portanto, do coração e das grandes veias que a ele se conectam, mas também do pulmão contralateral.

\section{4- FISIOPATOLOGIA}

As alterações cardiovasculares e o quadro clínico do choque embasam se em muitos mecanismos fisiopatológicos, imbricados entre si, conforme exposto na Figura 2, e que se expressam em intensidade variável, culminando com o aparecimento de hipoperfusão orgânica, quase sempre, associada à intensa hipotensão arterial.

Apesar da hipoperfusão tissular poder ser detectada e avaliada pelo exame clínico cuidadoso e seriado, é usual considerar a pressão arterial sistêmica a variável clínica mais significativa tanto no diagnóstico quanto na evolução do choque circulatório. Isso não significa que outras variáveis cardiocirculatórias de avaliação até mais simples, por exemplo, freqüência e

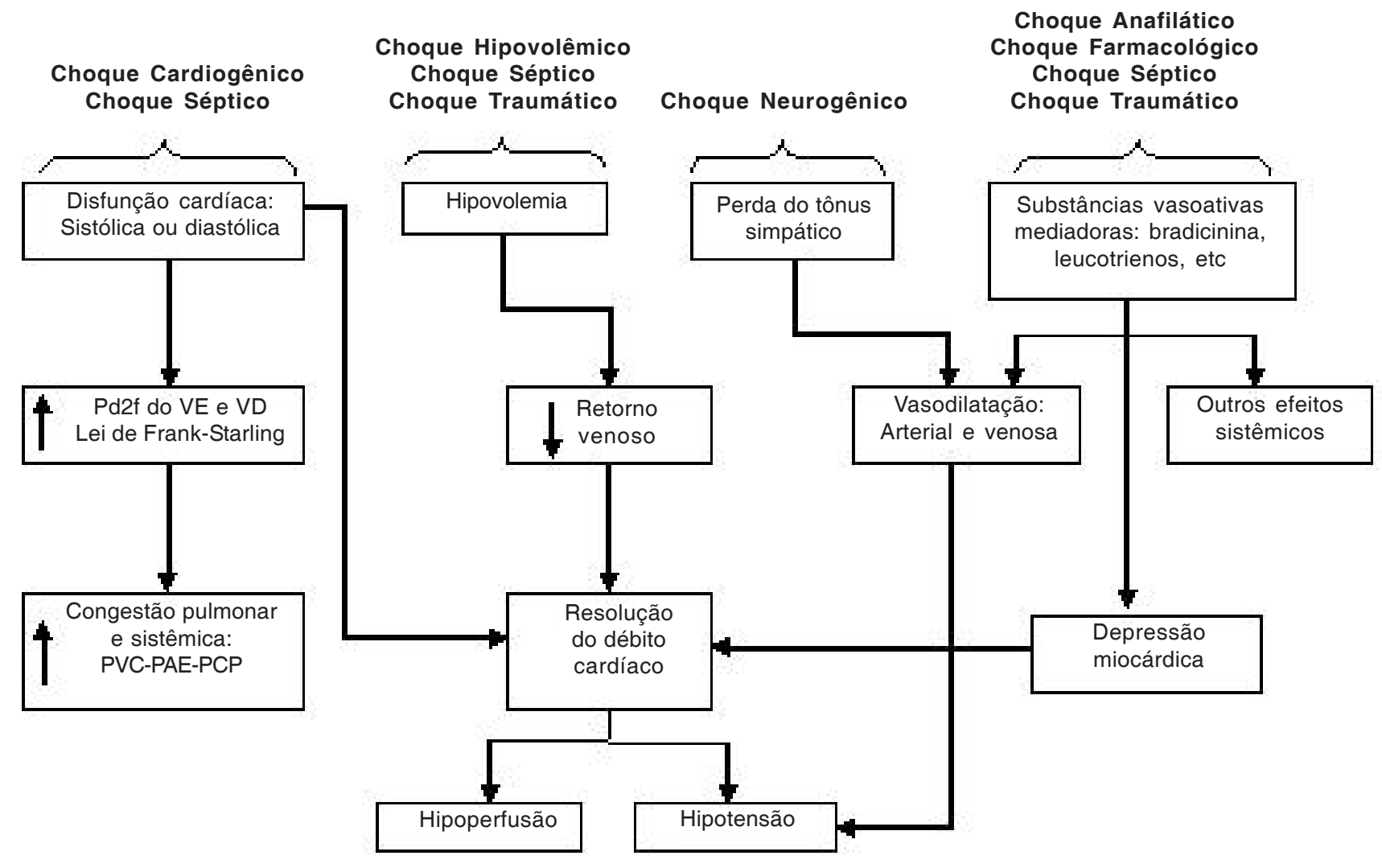

Figura 2: Eventos fisiopatológicos básicos do choque circulatório. 
intensidade do pulso arterial periférico, sejam menos importantes, ou que certas variáveis de obtenção mais elaborada, como a pressão venosa central ou o índice cardíaco, sejam menos informativas, mas sim, que a medida da pressão arterial, desde muito cedo, passou a ser reconhecida por médicos e, principalmente, paramédicos, como um sinal de alarme, na avaliação de pacientes em estado crítico, uma vez que se via como habitual e menos preocupante a aceleração dos batimentos cardíacos, comumente presente em muitos outros estados mórbidos agudos.

Em que pese considerar que a lesão orgânica progressiva determinada pelo choque circulatório decorra, na verdade, de insuficiente fluxo sangüíneo tecidual para prover nutrientes e eliminar escórias celulares e que a maioria das unidades de terapia intensiva conte com suporte laboratorial para acompanhar as alterações metabólicas e gasométricas decorrentes do choque, é preciso, no entanto, compreender, com clareza, as alterações hemodinâmicas subjacentes, mesmo porque, é de sua readequação, por meio de diferentes agentes terapêuticos que, em geral, se conseguirá reajustar o quadro hemodinâmico, com a sobrevivência do paciente.

Na Figura 3A observa se, esquematicamente, a redução do sistema circulatório a um circuito hidrodinâmico simples, constituído de uma bomba (coração), que propulsiona o sangue através de um tubo, representativo de toda rede vascular, e que interliga a aorta ascendente com o átrio direito.

Com base na analogia existente na Figura 3, A e $\mathrm{B}$, pode se considerar que o coração tem função semelhante à do gerador de corrente elétrica, conquanto a rede vascular, representada pelo tubo, corresponde à fiação interposta entre os dipolos do gerador. Aplicando se a lei de $\mathrm{Ohm}(\mathrm{V}=\mathrm{Ri})$ ao diagrama apresentado em C, e substituindo se na equação, o gradiente elétrico $(\mathrm{V})$, pela diferença de pressão entre a raiz da aorta (PAo) e o átrio direito (PAD), e a corrente elétrica (i), pelo volume sangüíneo ejetado pelo coração por unidade de tempo, denominado volume minuto circulatório (VMC), obtém se a equação [1]:

$$
(\mathrm{PAo} \text { PAD })=\text { Resistência } \mathrm{x} \mathrm{VMC}^{1}
$$

Como estamos nos referindo à circulação sistêmica, o valor da resistência corresponde à resistência vascular sistêmica (RVS), daí surgindo a fórmula [2]:

$$
(\mathrm{PAo} \mathrm{PAD})=\mathrm{RVS} \times \mathrm{VMC}^{2}
$$

Dada a ordem de grandeza da pressão na raiz da aorta, muito superior à da existente no átrio direito, pode se simplificar o termo à esquerda da equação, substituindo-o, simplesmente, pelo valor da pressão na raiz da aorta (PAo) [3]:

$$
\mathrm{PAo}=\mathrm{RVS} \times \mathrm{VMC}^{3}
$$

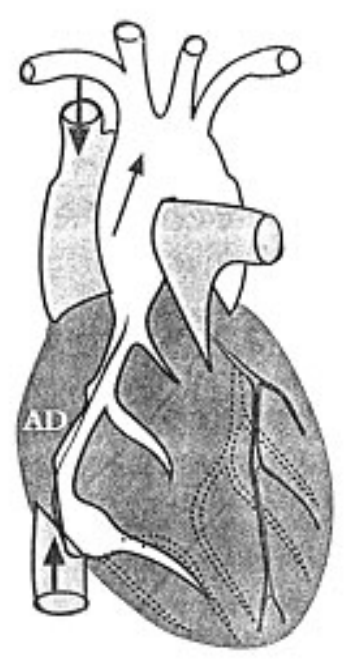

A

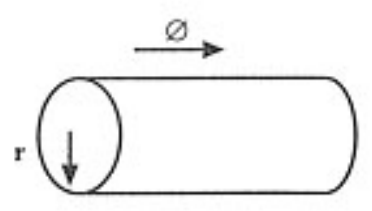

B

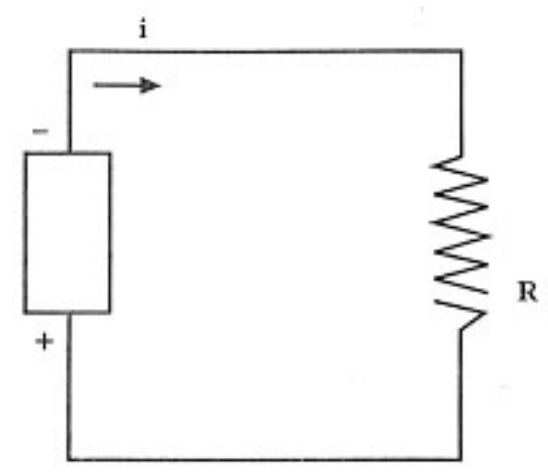

C

Figura 3: Esquema simplificado do aparelho circulatório (A); da vazão de fluidos por tubo e secção circular (B); e de um circuito elétrico simples $(C)$. 
O VMC corresponde, por sua vez, à multiplicação do volume sangüíneo ejetado por sístole (VS) pela frequiência cardíaca $(\mathrm{FC})$, conforme a fórmula seguinte [4]:

$$
\mathrm{VMC}=\mathrm{VS} \times \mathrm{FC}^{4}
$$

Por essa razão, a fórmula [3] pode ser grafada como [5]:

$$
\mathrm{PAo}=\mathrm{RVS} \times \mathrm{VS} \times \mathrm{FC}^{5}
$$

O VS, por seu turno, corresponde à multiplicação do volume diastólico final (ou de enchimento) do ventrículo esquerdo, por um fator representativo da condição contrátil do miocárdío ventricular, comumente designado contratilidade miocárdica (CM), fato expresso na fórmula [6]:

$$
\mathrm{VS}=\mathrm{VD} \times \mathrm{CM}^{6}
$$

Com base nessa informação, a fórmula [5] pode ser modificada, obtendo se a fórmula [7]:

$$
\mathrm{PAo}=\mathrm{RVS} \times \mathrm{VD} \times \mathrm{CM} \times \mathrm{FC}^{7}
$$

Por outro lado, POISEUILLE, a partir de experimentos com vazão de fluidos em tubulações rígidas de secção circular transversa, como a esquematizada na Figura 3 B, elaborou a fórmula [8], representativa do fluxo de fluidos por tubulações cilíndricas, análogas aos vasos sangüíneos.

$$
\text { Fluxo }=\frac{\left(\mathrm{P}^{1}-\mathrm{P}^{2}\right)-\pi \times \mathrm{R}^{4}}{8 \times \mathrm{L} \times \mu} \text { viscosidade }^{8}
$$

Transpondo se essa fórmula para o esquema da circulação representado na Figura 3, A, pode se entender o fluxo como representativo do fluxo sangüíneo, ou, melhor dizendo, do volume minuto circulatório (VMC), ao passo que o gradiente de pressão entre as extremidades do tubo seria, mais uma vez, representado apenas pela PAo, obtendo-se então, a fórmula [9]:

$$
\text { VS } \times \text { FC }=\frac{\text { PAo } \times \mathrm{R}^{4}}{8 \times \mathrm{L} \times \text { viscosidade }} \text { viscosidade }^{9}
$$

Isolando se a PAo à esquerda, chega se, finalmente, à fórmula da pressão arterial sistêmica [10], que passaremos a comentar.

$$
\text { PAo }=\frac{\text { VD x CM x FC x L x viscosidade x } 8}{\mathrm{R}^{4} \times \pi} 10
$$

Deve se atentar, inicialmente, para o fato de que o termo:

$$
\frac{\mathrm{L} \text { x viscosidade x } 8}{\mathrm{R}^{4}}
$$

presente na fórmula [10], é a representação matemática da resistência vascular sistêmica.

A fórmula [10] permite analisar os efeitos decorrentes da interação dos vários fatores responsáveis pelas alterações pressóricas observadas no choque circulatório e, por esse motivo, deve ser de pleno domínio de todos os médicos interessados em tratar pacientes nessa condição clínica.

Deve se, em particular, observar fato muito significativo na fórmula [10], o de que o raio dos vasos sangüíneos está elevado à quarta potência. Vale dizer que, se ocorrer vasodilatação com, por exemplo, duplicação do calibre vascular, a pressão arterial deveria sofrer queda imediata, extremamente acentuada, da ordem de 16 vezes. Felizmente, essa resposta é muito amortecida pela deflagração de outros mecanismos compensatórios, também reguladores da pressão arterial, como o de retroalimentação a partir dos receptores aórticos e carotídeos.

Diante do exposto, compreende se a grande importância de atentar para o estado de vasoconstrição ou vasodilatação periférica nos estados de choque. Pela mesma razão, explica se serem as drogas vasoconstritoras tão potentes em reverter a hipotensão arterial.

Em decorrência da ativação de circuitos de retroalimentação cardiovascular desencadeados pela hipotensão arterial, são necessários grande discernimento e ponderação ao proceder à analise da situação hemodinâmica num determinado momento, sendo mais prudente e prático observá la ao longo do tempo, à medida que se adotam medidas terapêuticas, procurando levar em consideração o comportamento do maior número possível de variáveis clínicas envolvidas no controle da pressão arterial sistêmica.

No choque hipovolêmico, cuja fisiopatologia é de mais fácil entendimento, o fator desencadeante primordial, a redução aguda do volume intravascular, 
é detectado tanto pelos receptores cardíacos responsivos ao grau de distensão das câmaras atriais, como pelos baro e quimioreceptores aórticos e carotídeos, e pelos corpúsculos renais justaglomerulares, deflagrando se complexa resposta neuroendócrina envolvendo maior produção de hormônio natriurético atrial, estimulação do sistema nervoso simpático e liberação de vasopressina pela hipófise, hormônio esse que, além de efeito antidíurético, também é potente vasoconstritor arteriolar.

Como hipovolemia acaba se instalando em, praticamente, todas as formas de choque circulatório, em razão do seqüestro extravascular decorrente da redução da pressão coloidosmótica do plasma e/ou pelo aumento da permeabilidade capilar, essa complexa resposta neuroendócrina, é também compartilhada pelas demais formas de choque circulatório, e tem por finalidade última garantir a perfusão do sistema nervoso central e do coração, graças ao restabelecimento da volemia, à redistribuição do volume circulante $\mathrm{e}$ ao aumento do rendimento cardíaco.

É preciso salientar a grande importância de quatro variáveis do metabolismo do oxigênio: a pressão e a saturação arteriais sistêmicas e venosas mistas de oxigênio $\left(\mathrm{p}_{\mathrm{a}} \mathrm{O}_{2}\right.$ e $\mathrm{S}_{\mathrm{a}} \mathrm{O}_{2}$, e pvO2 e $\left.\mathrm{SVO}_{2}\right)$, as duas primeiras reflexivas da habilidade pulmonar em oxigenar o sangue, e as duas últimas demonstradoras do balanço tecidual entre a oferta e o consumo tecidual de oxigênio. Valores de $\mathrm{pvO}_{2}$ e $\mathrm{SvO}_{2}$ inferiores, respectivamente, a $45 \mathrm{mmHg}$ e a $35 \%$, são preocupantes sinais de gravidade na vigência de oxigenação adequada do sangue arterial sistêmico, pois indicam grave hipoperfusão com baixa oferta tecidual de oxigênio. Essa situação decorre de índice cardíaco baixo e acompanha se, também, pela elevação do lactato sérico, resultante da ativação do metabolismo anaeróbio.

A redução na perfusão do sistema nervoso central durante hipotensão grave causa também intensa estimulação direta do sistema nervoso simpático, comandando a liberação de adrenalina pela camada medular supra renal e de noradrenalina na intimidade de vários tecidos, resultando em taquicardia, aumento do inotropismo cardíaco e vasoconstrição arterial e venosa.

A estimulação da secreção de renina pelas células justaglomerulares renais resulta na maior formação de angiotensina, que, além de vasoconstrição arteriolar, diminui a excreção renal de água e eletrólitos devido à estimulação da secreção de aldosterona pelo córtex supra renal (Figura 4).

Cabe também considerar que a ativação do sistema reticuloendotelial desencadeada pela lesão tecidual (infecção, traumatismo, queimadura, etc.) pode, por razões ainda a esclarecer, exacerbar se, deflagrando resposta inflamatória sistêmica ampliada e potencialmente fatal, atualmente conhecida como síndrome da resposta inflamatória sistêmica (SRIS).4,6

Essa síndrome caracteriza se por duas ou mais das seguintes manifestações clínicas:

- Temperatura central $>38^{\circ} \mathrm{C}$ ou $<36^{\circ} \mathrm{C}$

- Freqüência cardíaca $>90 \mathrm{bpm}$

- Frequiência respiratória $>20 \mathrm{resp} / \mathrm{min}$

- $\mathrm{p}_{\mathrm{a}} \mathrm{CO}_{2}<32 \mathrm{mmHg}$

- Contagem de leucócitos $>12.000 \mathrm{~mm}^{3}$ ou $<4.000 \mathrm{~mm}^{3}$, ou percentual de células imaturas (desvio à esquerda) $>10 \%$

A hipertermia, embora das manifestações mais comuns, pode não ocorrer, sobretudo em idosos e no choque avançado, situações essas que, geralmente, cursam com hipotermia sistêmica. Evidências de vasculite, como petéquias cutâneas e conjuntivas, necrose de extremidades, tromboflebites e linfangites, podem ser detectadas em quadros infecciosos graves. A taquicardia também é sinal freqüente, a não ser quando obstada pela presença de distúrbios do sistema de condução intracardíaco. A hipotensão e sinais explícitos de hipoperfusão, embora possam estar ausentes quando o quadro se instala, levam, à medida que o paciente piora, à oligúria ou mesmo anúria, à acidose láctica e à alteração do estado mental.

$\mathrm{Na}$ presença de sepse, a disfunção do órgão alvo da infecção, como por exemplo a insuficiência respiratória, na pneumonia, pode mesclar se com a agressão dos mediadores da SRIS, ao mesmo tempo em que passam a se exprimir as demais manifestações sistêmicas da síndrome. Destas, as mais comuns são a síndrome da angústia respiratória do adulto (SARA), a insuficiência renal, a disfunção do sistema nervoso central e a insuficiência hepática. Esta última, comumente, deve se ao desenvolvimento de hepatite transinfecciosa, nos casos de sepse, ou à síndrome hepatorrenal, nas situações em que pareça inexistir quadro séptico.

Dentre os achados laboratoriais mais freqüentes, incluem se elevação de bilirrubinas e transaminases, bem como dos tempos de tromboplastina parcial ativada, tempo de protrombina, de creatinina e de uréia plasmáticas. Leucocitose com desvio à esquerda, ou leucopenia, trombocitopenia, hiperglicemia e acidose metabólica são achados freqüentes. Nas fases iniciais da disfunção respiratória surge hipoxemia associada à hipocapnia, mas à medida que a disfunção pulmonar se acentua, instala se hipercapnia. 


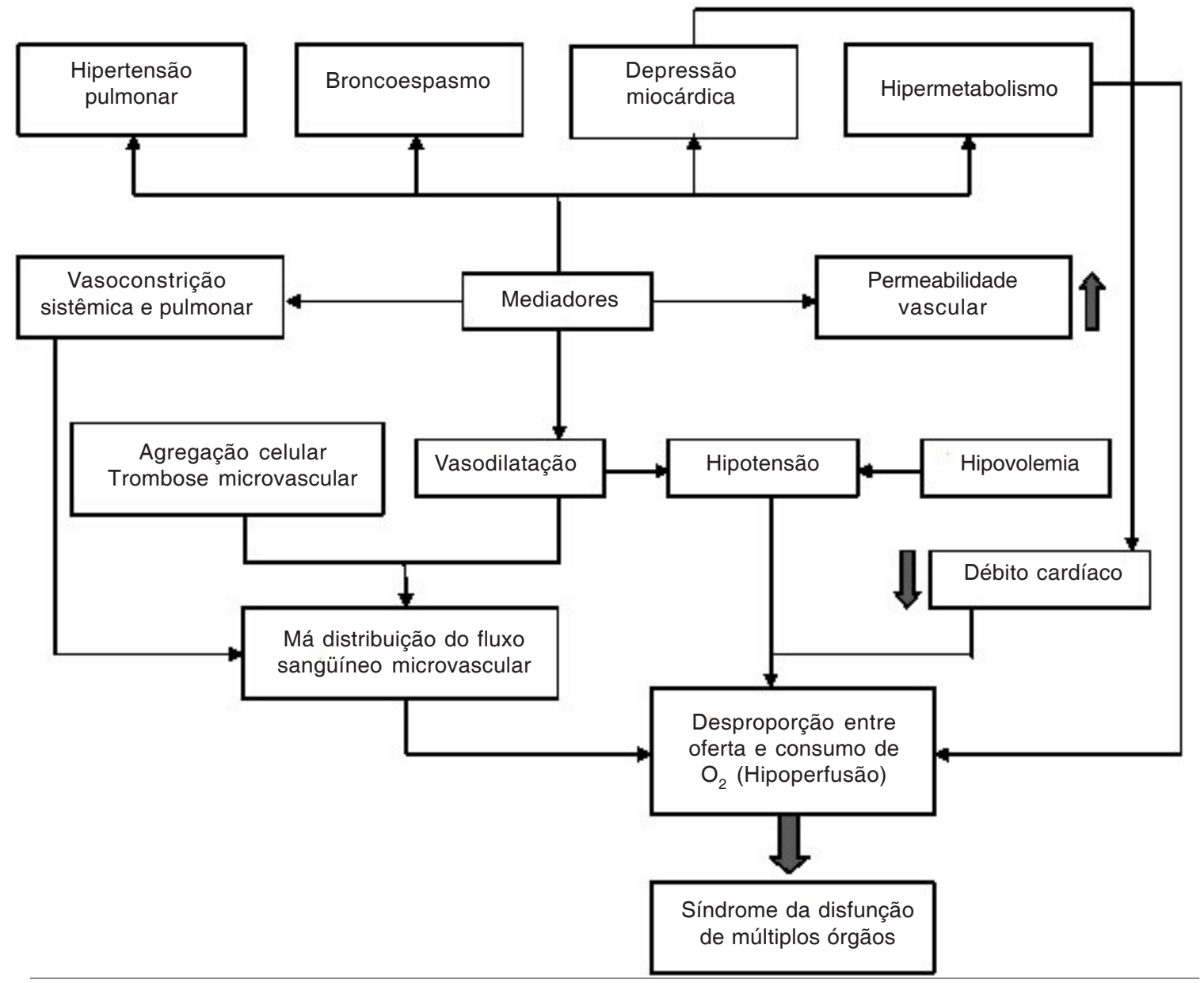

Figura 4: Eventos desencadeados pelos mediadores inflamatórios da SRIS.

Recentemente $^{9}$, aventou se a hipótese, denominada "two hit", de que seriam necessários eventos agressores seqüenciais para desencadear se a SRIS, o primeiro dos quais iniciaria o processo inflamatório e o segundo modularia a resposta inflamatória sistêmica, tornando a desproporcional e exagerada.

Sabe se que as citocininas, sobretudo as interleucinas (IL-1 e IL 6), o fator de necrose tumoral, interferons e outras substâncias são mediadores humorais chaves na resposta inflamatória inicial. Esses mediadores, atuando juntamente com agentes celulares, como os polimorfonucleares, macrófagos, monócitos e células endoteliais, ativam e recrutam diversos outros sistemas que participam na resposta inflamatória, dentre os quais destacam se a cascata de coagulação, a agregação e degranulação plaquetária, o sistema complemento, a ativação de mastócitos e o sistema da bradicinina (Figura 4).

Embora a SRIS se acompanhe, quase sempre, de hipotensão, o débito cardíaco normalmente está aumentado, sobretudo nas fases iniciais. Isso se dá em resposta ao estado de hipermetabolismo e da queda na pós carga por vasodilatação arteriolar, particularmente se já iniciada a terapêutica de reposição volêmica, com correção da hipovolemia.

A má perfusão tecidual explica se não somente pela hipotensão, mas também, e principalmente, por alterações na distribuição do fluxo sangüíneo no nível da microcirculação ${ }^{4}$, de modo a interferir tanto no metabolismo tecidual quanto na auto regulação local do fluxo sangüíneo. Obviamente, à medida que surgem disfunções orgânicas, inclusive cardíaca, sobretudo na presença de hipovolemia, há deterioração progressiva do quadro clínico, com redução progressiva do volume minuto cardíaco.

No choque anafilático, em particular, a degranulação de basófilos e mastócitos estimulada pelo complexo IgE-antígeno, previamente sensibilizado, libera histamina, serotonina, enzimas proteolíticas e outros mediadores, tais como leucotrienos e metabólitos da via da cicloxigenase que, em conjunto, deflagram uma série de manifestações clínicas potencialmente letais. 


\section{QUADRO CLÍNICO}

O choque circulatório, independentemente da etiologia, acompanha se de oligúria e hipotensão arterial (Figura 5). Esta última, dependendo do grau de hipovolemia presente, pode ser evidenciada apenas na posição ortostática. A pressão venosa central e a pressão capilar pulmonar, que reflete o enchimento diastólico do ventrículo esquerdo, habitualmente, estão baixas, com exceção feita aos casos de choque por insuficiência com comprometimento cardíaco.

A hipotensão arterial é caracterizada por pressão arterial sistólica inferior a $90 \mathrm{mmHg}$ ou mais de $40 \mathrm{mmHg}$ abaixo da pressão arterial sistólica habitual do paciente.

Nos casos de perda sangüínea expressiva, a hiperatividade simpática traduz se por pulsos finos, taquicardia, frialdade das extremidades, palidez cutaneomucosa, sudorese e oligúria, constituindo o aumento da diurese valioso indicador da melhora da perfusão tecidual, à medida que se repõe a volemia.

O nível de consciência costuma estar rebaixado nos pacientes com hipoperfusão grave do sistema nervoso central (SNC), hipoxemia ou traumatismo crânio-encefálico. Todavia, sobretudo nos politraumatizados jovens, pode, pelo contrário, cursar com agitação psicomotora, importante sinal de alerta para o médico.

Os achados laboratoriais refletem a hipoperfusão tecidual, expressa por redução da $\mathrm{p}_{\mathrm{v}} \mathrm{O} 2$ e da $\mathrm{S}_{\mathrm{v}} \mathrm{O}_{2}$, acidose metabólica, elevação da creatinina plasmática e rebaixamento dos níveis hematimétricos, nos casos de sangramento, ou em decorrência de reposição volêmica não-sangüínea. O hematócrito, por outro lado, eleva-se quando a perda volêmica não envolve os elementos figurados.

No choque por descompensação diabética, a intensa desidratação, o hálito e o odor cetônico da urina, juntamente com antecedentes diabéticos, apontam claramente para o diagnóstico dessa grave condição.

O choque anafilático é caracterizado por broncoespasmo, aumento da secreção da mucosa respiratória, laringoespasmo, vasoconstrição pulmonar, hipotensão, taquicardia, aumento da permeabilidade capilar, síncope, convulsões, letargia, podendo complicar se com coagulação intravascular disseminada. Somam-se, a estas, outras manifestações menos gra-

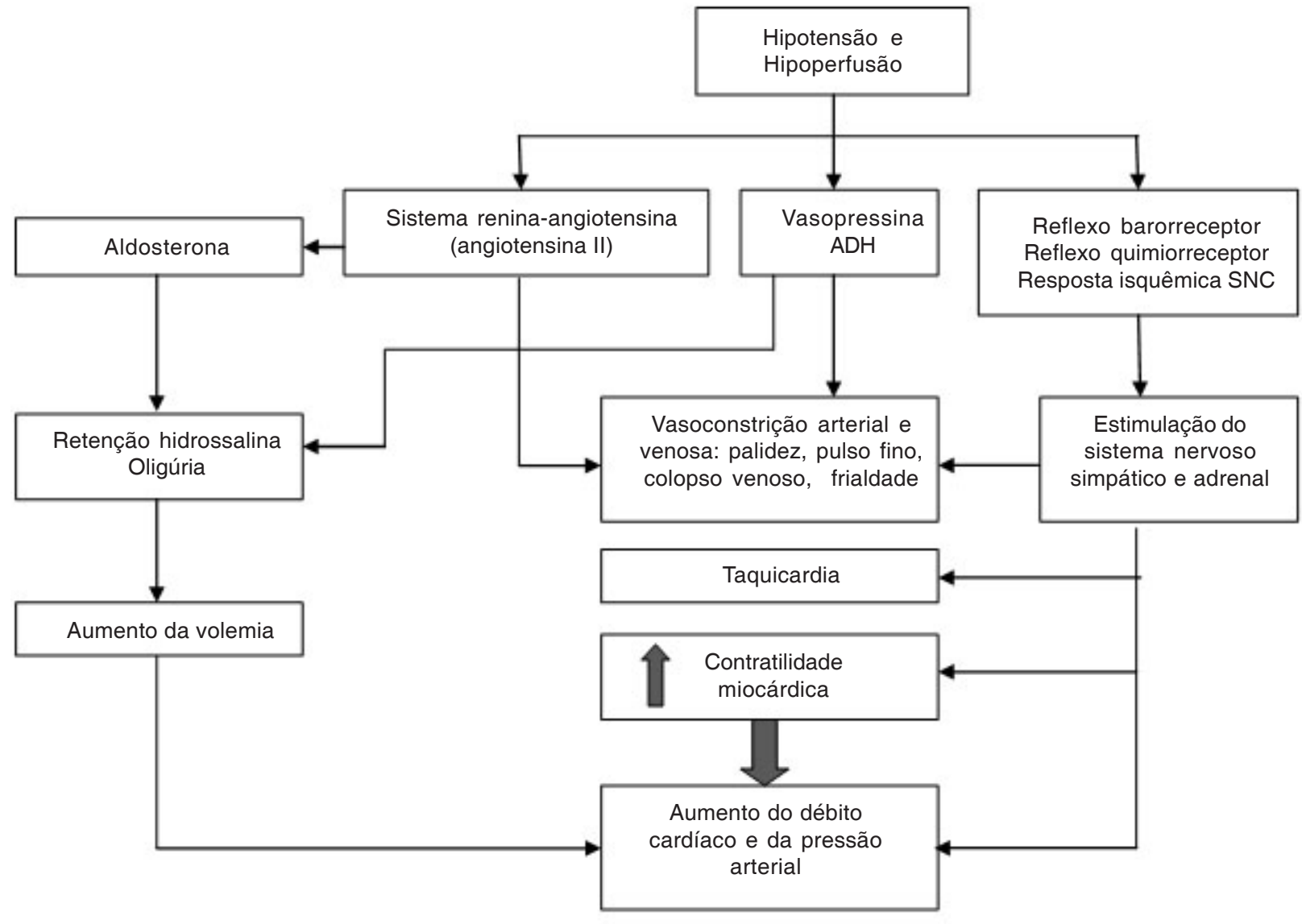

Figura 5: Resposta neuro hormonal à hipotensão arterial e à hipoperfusão do sistema nervoso central. 
ves, como urticária, angioedema, eritema cutaneo-conjuntivo, lacrimejamento, náusea, vômito, diarréia, dor abdominal.

É preciso ter em conta que os sintomas podem ocorrer dentro de segundos a minutos após a exposição ao antígeno, e ter caráter bifásico, pois, algumas horas após o sucesso terapêutico inicial, podem ressurgir manifestações graves.

\section{TRATAMENTO}

O tratamento do choque visa, simultaneamente, à eliminação dos fatores desencadeantes e à normalização da perfusão tissular e da oferta tecidual de oxigênio. ${ }^{5,10}$.

O sucesso terapêutico depende, na maioria dos casos, da presteza, lucidez e agressividade com que se tomam medidas terapêuticas, particularmente a reposição volêmica vital à otimização do enchimento ventricular, refletidas, na prática clínica, no ajuste fino da PVC e da PCP, pois o leitor deve sempre lembrar que o coração, como bomba motriz obediente à lei de Frank Starling, já abordada anteriormente, depende do enchimento diastólico ventricular para aumentar o volume sistólico e, em decorrência, o volume minuto cardíaco, na ausência de outros fatores estimulantes da contratilidade miocárdica.

Como lesões traumáticas graves podem, com frequiência determinar choque traumático e morte, quando não tratadas adequadamente, tem se preconizado, e exigido, há vários anos, o treinamento de mé- dicos traumatologistas e intensivistas em cursos específicos sobre o assunto.

No choque cardiogênico, o prognóstico é sombrio, com alta taxa de mortalidade, de 50 a $80 \%$. Cabem nessa entidade métodos específicos de tentativas de salvamento do miocárdio isquêmico peri-infarto ou mesmo localizado à distância, com angioplastia percutânea, infusão de trombolíticos, revascularização cirúrgica associada à contrapulsação aórtica, ou mesmo implante de ventrículos artificiais de cunho definitivo ou como ponte para o transplante cardíaco.

A hipovolemia presente no choque séptico requer tática de reposição volêmica gradual, mediante a infusão de alíquotas de 250 a $500 \mathrm{ml}$ de solução cristalóide ou colóide, a intervalos de 10 a $15 \mathrm{~min}$, Em razão da depressão da função cardíaca que pode estar presente, é aconselhável a monitoração da pressão capilar pulmonar mediante cateter de Swan Ganz. A pressão capilar pulmonar pode ser elevada até $18 \mathrm{mmHg}$, para otimizar a pré carga e, conseqüentemente, o volume minuto cardíaco, desde que a pressão coloidosmótica esteja normal, Ainda com vistas a otimizar a oferta tecidual de oxigênio, é prudente, além de garantir a saturação da hemoglobina arterial sistêmica, manter o hematócrito acima de $30 \%$.

Quando a otimização da volemia é insuficiente para a normalização do quadro hemodinâmico, iniciam se drogas vasoativas, sendo as mais freqüentemente utilizadas em nosso meio a dopamina, a dobutamina, a adrenalina e a noradrenalina, cujas doses e efeitos ${ }^{17}$ estão resumidos na Tabela I.

\begin{tabular}{|c|c|c|c|}
\hline Droga & Dose $(\mu / \mathrm{kg} / \mathrm{min})$ & $\begin{array}{l}\text { Receptor predominan- } \\
\text { temente estimulado }\end{array}$ & Efeito \\
\hline Dopamina & $\begin{array}{l}13 \\
2,5 \text { a } 6 \\
>6\end{array}$ & $\begin{array}{c}\text { Dopaminérgico } \\
\beta \\
\alpha\end{array}$ & $\begin{array}{c}\text { Diurese } \\
\text { Aumento do VMC* e vasodilatação } \\
\text { Vasoconstrição }\end{array}$ \\
\hline Dobutamina & 515 & $\beta$ & Aumento do VMC e vasodílatação \\
\hline Adrenafina & $\begin{array}{l}<0,03 \\
0,030,15 \\
>0,15\end{array}$ & $\begin{array}{c}\beta \\
\alpha \text { e } \beta \\
\alpha\end{array}$ & $\begin{array}{c}\text { Aumento do VMC e vasodílatação } \\
\text { Misto } \\
\text { Vasoconstrição }\end{array}$ \\
\hline Noradrenalina & $\begin{array}{c}0,010,05 \\
>0,05\end{array}$ & $\begin{array}{c}\alpha \text { e } \beta \\
\alpha\end{array}$ & $\begin{array}{c}\text { Misto } \\
\text { Vasoconstrição }\end{array}$ \\
\hline
\end{tabular}

* Modificado de Wagner, B.K.J. - Drug monitoring In: Ayres, S.M.; Shoemacker, W.C.; Grenvik, A.; Holbrook, P.R.. - Textbook of Critical Care, 3rd ed., Philadelphia, W.B., Saunders, 1995. 
A escolha da droga depende da experiência pessoal do médico e da condição do paciente. Geralmente, inicia se com dopamina em dose $\beta$-adrenérgica, podendo se elevar a taxa de infusão até se atingir efeito $\alpha$-adrenérgico. A dobutamina, em geral, é associada à dopamima quando são necessárias doses relativamente elevadas desta última, na tentativa de que seus efeitos inotrópicos sinérgicos possam melhorar ainda mais o débito cardíaco.

Como primeira escolha, a utilização isolada de dobutamina é reservada aos pacientes normotensos ou cuja hipotensão seja, apenas, discreta, após se ter procedido a reposição volêmica, e nos quais se deseja aumentar o débito cardíaco decorrente de indicativos de hipoperfusão orgânica (oligúria, lactato elevado, disfunção orgânica). Reservam-se a adrenalina e a noradrenalina para os casos em que, apesar da reposição volêmica e de doses máximas de dopamina e dobutamina, permanecem a hípotensão e a hipoperfusão. Em razão da vasoconstrição arteriolar esplâncnica, sobretudo renal, provocada por essas drogas, muitas vezes se lhes associa dopamina em dose dopaminérgica, na tentativa de manter a perfusão renal.

Deve se atentar, por outro lado, à maximização do aporte de oxigênio pelos pulmões. Esta última medida requer pleno domínio da fisiologia respiratória, pois envolve imensa gama de medidas, desde a mais simples, a suplementação nasal de oxigênio até a intubação traqueal com ventilação mecânica, podendo, alguns centros, até mesmo dispor de oxigenação extracorpórea com oxigenador de membrana, nos casos extremos.

Alguns advogam a hipercorreção da oferta tecidual de oxigênio, particularmente nos casos de choque distributivo, recomendando manter-se o índice cardíaco acima de $4,51 / \mathrm{min} / \mathrm{m}^{2}$ e o índice de oferta tecidual de oxigênio $\left(\mathrm{DO}_{2}\right)$ acima de $600 \mathrm{ml} / \mathrm{min} / \mathrm{m}^{2}$, a fim de que o índice de consumo de oxigênio $\left(\mathrm{VO}_{2}\right)$ permaneça acima de $170 \mathrm{ml} / \mathrm{min} / \mathrm{m}^{2}$. ${ }^{2,11,12}$

Todavia, não existe consenso acerca das variáveis fisiológicas mais adequadas para avaliação da perfusão tecidual. ${ }^{10} \mathrm{~A}$ aferição da relação entre a oferta e o consumo de oxigênio, ${ }^{11,12}$ assim como métodos tonométricos para a aferição da $\mathrm{pCO} 2$ e do $\mathrm{pH}$ da mucosa gastrointestinal, ${ }^{10,15}$ bem como métodos de medida do fluxo sangüíneo tecidual por espectroscopia próxima ao infravermelho ${ }^{14}$ foram propostos.

O acompanhamento e correção dos distúrbios eletrolíticos e ácido básicos, sobretudo a acidose metabólica, são, entretanto, outras medidas práticas im- portantes, a fim de propiciar melhores condições homeostáticas, essenciais às funções bioquímicas celulares.

A nutrição adequada, preferencialmente por via enteral, além de evitar a rápida desnutrição a que esses pacientes estão sujeitos, contribui para a vitalidade da mucosa gastrointestinal, de modo a impedir o aparecimento de úlceras de estresse e a translocação bacteriana. Quando a nutrição enteral não puder ser implementada, cabe salientar a importância dos bloqueadores da secreção ácida do estômago, em que pese o efeito colateral facilitador da contaminação desse órgão em decorrência da hipocloridria.

A diálise peritoneal ou a hemodiálise deve ser implementada sem perda de tempo quando a insuficiência renal fugir do controle clínico.

A controvérsia quanto às soluções mais adequadas para a reposição volêmica, se colóides ou cristalóides, persiste, sobretudo nos casos de choque traumático, pois parece não haver diferença entre elas no que se refere ao aparecimento de edema pulmonar, mortalidade e tempo de internação ${ }^{3}$

Em vista dos custos elevados e dos riscos envolvidos nas transfusões de sangue e derivados, atualmente, tem se procurado racionalização de sua utilização, ${ }^{8,13}$ obedecendo os critérios resumidos no Quadro 1.

Todo o esforço deve ser feito para a erradicação da infecção por meios clínicos e/ou cirúrgicos. Cateteres vasculares, drenos e sondas suspeitos devem ser retirados ou substituídos, sempre submetendo os ao exame microbiológico.

A investigação do(s) microrganismo(s), responsável (is) pela infecção é necessária para a instituição da terapia antimicrobiaria. Caso aquela não traga subsídios, ou demore a ser obtida, deve se instituir antibioticoterapia de amplo espectro, levando se em consideração as disfunções orgânicas associadas, o local da infecção e o conhecimento das infecções hospitalares mais comuns na instituição.

No choque anafilático, condição muito alarmante e potencialmente fatal, em curto espaço de tempo, ${ }^{16}$ deve se afastar imediatamente o agente desencadeante. Caso se trate de droga, interrompe se a infusão tão logo surjam sinais e sintomas sugestivos de anafilaxia. A terapêutica padrão inclui a administração de adrenalina, anti histamínicos, bloqueadores $\mathrm{H}_{2}$ e corticóides.

A adrenalina deve ser administrada na dose de $0,3 \mathrm{ml}$ de solução $1: 1000$, no subcutâneo $(0,01 \mathrm{mcg} / \mathrm{kg}$ 


\section{Quadro 1. Critérios para transfusão de hemoderivados no tratamento do choque*}

\section{Critérios para a transfusão de concentrado de hemácias}

1. Pacientes de alto risco para eventos isquêmicos (AVC, infarto agudo do miocárdio, etc.) Hemoglobina inferior a $6 \mathrm{~g} / \mathrm{dl}$ usualmente necessária; 6 a $10 \mathrm{~g} / \mathrm{dl}$ depende da condição do paciente; superior a $10 \mathrm{~g} / \mathrm{dl}$ raramente necessária.

* Taquicardia e hipotensão não corrigidas por reposição volêmica, $\mathrm{p}_{\mathrm{v}} \mathrm{O}_{2}$, inferior a $25 \mathrm{mmHg}$, extração de $\mathrm{O}_{2}$ superior a $50 \%$ e $\mathrm{VO}_{2}$ inferior a $50 \%$ do basal geralmente é necessária.

\section{Critérios para a transfusão de plasma fresco congelado}

1. Perda sanguínea igual ou maior que uma volemia.

2. Definitivamente indicada para perda superior a $150 \%$ da volemia.

Quando a deterioração da hemostasia normal é antecipada ou se torna evidente, a rápida infusão de 4 a 5 unidades de plasma fresco deve ser utilizada, no adulto, ou 4 unidades para cada 6 de concentrado de hemácias.

- O TTPa e TP só têm valor se 1,5 vez maiores que o esperado e associados a sangramento anormal.

- Devido à alta concentração de citrato deve se monitorar o cálcio plasmático.

\section{Critérios para a transfusão de crioprecipitado}

Geralmente, suficiente fibrinogênio é reposto com a transfusão de plasma fresco, devendo reservar se a transfusão de crioprecipitado quando se documenta hipofibrinogenemia.

\section{Critérios para a transfusão de concentrado de plaquetas}

1. Como o surgimento de plaquetopenia é imprevisível, deve se monitorar a contagem de plaquetas.

2. A contagem plaquetária deve ser mantida acima de 50.000 durante operações de grande porte, todavia tem se recomendado que em pacientes com extensos traumas de alta energia a contagem seja mantida acima de 100.000. - Geralmente utilizam se de 8 a 12 unidades para um adulto de $75 \mathrm{~kg}$.

*Baseado em Simon TL et al. Practice parameter for the use of red blood cell transfusions: developed by the Red Blood Cell Administration Practice Guideline Development Task Force of the College of American Pathologists. Arch pathol lab med, 122: 130-8, 1998.

na criança), e repetida a intervalos de $15 \mathrm{~min}$, se necessário, nos casos leves a moderados. Nos casos graves, com hipotensão alarmante ou ausência de pulso palpável, infundem se por via endovenosa até $3 \mathrm{ml}$ de solução de adrenalina a 1:10.000, nos adultos. Acesso venoso central e monitoração invasiva da pressão arterial são desejáveis na continuidade do tratamento desses casos.

Anti histamínico (bloqueador H1) é iniciado e mantido por, pelo menos, 48 horas. Em nosso meio estão disponíveis a prometazina, cuja dose é de 50mg, por via intramuscular, e a dextrocloroféniramina, na dose de $5 \mathrm{mg}$, pela mesma via.

A ranitidina (bloqueador $\mathrm{H} 2$ ), na dose $50 \mathrm{mg}$, por infusão lenta, endovenosa, é útil nos casos de hipotensão refratária à adrenalina e à reposição volêmica.

Embora corticosteróides não tenham efeito na fase aguda, faltem evidências clínicas consistentes, julga se que a hidrocortisona, na dose de 100 a 200mg IV, repetida a cada $6 \mathrm{~h}$, possa minorar a recorrência das manifestações.

No atendimento inicial é essencial manter as vias aéreas pérvias. Caso o edema de glote esteja pro- vocando dificuldade respiratória grave, não responsiva às medidas clínicas iniciais, impõe se intubação orotraqueal. Se esta não for conseguida, recorre se à cricotireotomia ou à punção da cartilagem cricóidea com agulha calibrosa. A traqueostomia, por envolver mais riscos e complicações, deve ser protelada para depois que uma dessas medidas já tiver sido executada e a situação esteja mais controlada.

A vasodilatação arterial e venosa, parte da resposta anafilática, causa hipovolemia relativa que requer correção com infusão endovenosa de solução cristalóide (solução salina 0,9\% ou de Ringer lactato) ou colóide. Caso a hipotensão persista após essa medida, inicia se infusão endovenosa contínua de adrenalina $(0,01 \mathrm{mcg} / \mathrm{kg} / \mathrm{min})$, dopamina ( $>6 \mathrm{mg} / \mathrm{kg} / \mathrm{min})$ ou noradrenalina ( 2 a $3 \mathrm{mcg} / \mathrm{min}$ ).

$\mathrm{O}$ broncoespasmo resistente à adrenalina e anti histaminicos pode melhorar com nebulização $\operatorname{com} \beta_{2}$ agonista ou infusão endovenosa de aminofilina, na dose de $5 \mathrm{mg} / \mathrm{kg}$, infundida em 30min, e seguida da infusão contínua de 0,3 a $0,9 \mathrm{mg} / \mathrm{kg}$.

Pacientes porventura em uso de $\beta$-bloqueadores podem não responder satisfatoriamente à admi- 
nistração de adrenalina. Nesse caso, recorre se à atropina, se houver bradicardia e broncoespasmo persistentes. A administração de glucagon, cujas ações não dependem de receptores $P$, na dose de 1 a $5 \mathrm{mg}$ $\mathrm{IV}$, durante $1 \mathrm{~min}$, seguido da infusão contínua de $1 \mathrm{a}$ $5 \mathrm{mg} / \mathrm{h}$, pode ser útil.
Antibióticos $\beta$-lactâmicos, alimentos, picadas de insetos e contrastes radiológicos são os veículos mais comumente implicados na gênese do choque anafilático. Por essa razão, deve se sempre investigar a exposição pregressa a esses agentes e a ocorrência de reações prévias a eles.

Vicente WVA, Rodrigues AJ, Silva Júnior JR. Circulatory Shock. Medicina (Ribeirão Preto) 2008; 41 (4): 437-48.

ABSTRACT: Practical physiological aspects of both the cardiovascular and the circulatory system, which help to give an insight into the hemodynamic abnormalities that underlie the different symptoms of circulatory shock, are presented. Furthermore, basic therapeutic methods for the treatment of circulatory shocks are discussed.

keywords: Shock. Shock/diagnosis. Circulatory Shock.

\section{BIBLIOGRAFIA RECOMENDADA}

1 - Abraham E, Matthay MA, Dinarello CA, Vincent JL, Cohen J, Opal SM, Glauser M, Parsons P, Fisher CJJR, Repine JE. Consensus conference definitions for sepsis, septic shock, acute lung injury and acute respiratory distress syndrome: time for a reevaluation. Crit care med. 28: 232-5, 2000.

2 - Bishop MH, Shoemaker WC, Appel PL, Meade P, Ordog GJ, Wasserberger J, et al. Prospective, randomized trial of survivor values of cardiac index, oxygen delivery, and oxygen consumption as resuscitation endpoints in severe trauma. $\mathrm{J}$ trauma. 38: 780-7, 1995.

3 - Choi p T, Yip G, Quinonez LG, Cook DJ. Crystalloids vs. colloids in fluid resuscitation: a systematic review. Crit care med. 7: 200-10, 1999.

4 - Davies MG, Hagen PO. Systemic inflammatory response syndrome. Br j surg. 84: 920-35, 1997.

5. Jimenez JE Shockin: Civeta JM, Taylor RW, Kirby RR. Critícal Care. 3rd ed., Philadelphia, Lippincott Raven, p. 359-412, 1997.

6 - Fry DE. Sepsis syndrome. Am surg. 66: 126-32, 2000.

7 - Hardaway RM. Traumatic shock alias posttrauma critical illness. Am surg. 66: 284-90, 2000.

8 - Hiippala S. Replacement of massive blood loss. Vox sang. 74 (suppl. 2) 2: 399-407, 1998.

9 - Meldrum DR, Cleveland JCJR, Moore EE, Patrick DA, Banerjee A, Harken AH. Adaptive and maladaptive mechanisms of cellular priming. Ann surg. 226: 587-98, 1997.

10 - Porter JM, Ivatury RR. In search of the optimal end points of resuscitation in trauma patients. J trauma. 44: 908-14, 1998.

11 - Shoemaker WC. Transporte e metabolismo do oxigênio no choque e na doença crítica. Monitorização invasiva e não invasiva da disfunção circulatória e do choque. In: Levy MM. Clínicas de Terapia Intensiva. Rio de Janeiro, Interlivros, vol. 4, p. 927-58, 1996.

12 - Shoemaker WC. Diagnosis and treatment of shock syndromes. In: Ayres S M, Shoemacker W C, Grenvik a, Holbrook P R. Têxtbook of Critical Care. 3rd ed., Philadelphia, Saunders, p. 85-102, 1995.

13 - Simon TL, Alverson DC, Aubuchon J, Cooper ES, Dechristopher PJ, Glenn GC, et al. Practice parameter for the use of red blood cell transfusions: developped by the Red Blood Cell Administration Practice Guideline Development Task Force of the College of American Pathologists. Arch pathol lab med. 122: 130-8, 1998.

14 - Simonson SG, Piantadosi CA. Espectroscopia próxima ao vermelho. Aplicações clínicas. In: Levy MM. Clínicas de Terapia Intensiva. Rio de Janeiro, Interlivros, vol. 4, p. 1011-34, 1996.

15 - Taylor ED, Gutierrez G. Tonometria. Uma revisão dos estudos clínicos. In: Levy MM. Clínicas de Terapia Intensiva. Rio de Janeiro, Interlivros, vol. 4, p. 997-1009, 1996.

16 - Nicklas RA, Bernstein IL, Li JT, Lee RE, Spector SL, Dykewicz MS, et al. The diagnosis and management of anaphylaxis Joint Task Force on Practice Parameters, American Academy of Allergy, Asthma and Immunology, American College of Allergy, Asthma and Immunology, and the Joint Council of Allergy, Asthma and Immunology. J allergy clin immunol. 101 (6 pt 2):465-528,1998.

17 - Wagner BKJ. Drug monitoring. In: Ayres SM, Shoemacker WG, Grenvik A, Holbrook PR. Textbook of Critical Care. 3rd ed., Philadelphia, WB. Saunders, p. 1154-63, 1995.

Recebido para publicação em 20/08/2008

Aprovado para publicação em 23/10/2008 